NASA Technical Memorandum 103264

\title{
Reliability Analysis of \\ a Structural Ceramic \\ Combustion Chamber
}

Jonathan A. Salem, Jane M. Manderscheid, Marc R. Freedman, and John P. Gyekenyesi

Lewis Research Center

Cleveland, Ohio

Prepared for the

36th International Gas Turbine and Aeroengine Congress and Exposition sponsored by the American Society of Mechanical Engineers

Orlando, Florida, June 3-6, 1991 


\section{RELIABILITY ANALYSIS OF A STRUCTURAL CERAMIC \\ COMBUSTION CHAMBER}

Jonathan A. Salem, Jane M. Manderscheid,

Marc R. Freedman, and John P. Gyekenyesi

National Aeronautics and Space Administration

Lewis Research Center

Cleveland, Ohio 44135

\section{ABSTRACT}

The Weibull modulus, fracture toughness, and thermal properties of a silicon nitride material used to make a gas turbine combustor were experimentally measured. The location and nature of failure origins resulting from bend tests were determined with fractographic analysis. The measured Weibull parameters were used along with thermal and stress analysis to determine failure probabilities of the combustor with the CARES design code. The effects of data censoring, FEM mesh refinement, and fracture criterion were considered in the analysis.

\section{INTRODUCT ION}

The need for more fuel efficient transportation and lower engine emissions has made ceramics increasingly important structural materials. Ceramics offer many beneficial properties, such as high-temperature strength, low density, and low thermal conductivity.

Ceramics, however, are brittle materials. Weibull statistics (1) are commonly used for reliability analysis of components fabricated from such materials. The calculated failure probability is dependent on the stress state and the material properties of the component. It is well-known, however, that this procedure is inadequate to describe experimental data obtained in multiaxial stress states (2).

The application of ceramics as structural components requires a more rigorous reliability theory. Such a theory should combine linear elastic 
fracture mechanics with established statistical failure theories. Several applicable theories have been incorporated into the public domain, Ceramics Analysis and Reliability Evaluation of Structures (CARES) (3) code developed at NASA Lewis. This post-processor code, when combined with a finite element method (FEM) stress analysis, calculates fast fracture probability of a brittle, monolithic structural component. CARES also calculates Weibull statistical parameters using data from simple mechanical tests such as four-point bending or tensile strength tests.

The objective of this paper is to demonstrate an analytical method for determining the mechanical properties and reliability of a ceramic component. The example component chosen for this analysis was a silicon nitride combustor designed for use in a ceramic gas turbine (CGT) engine.

COMBUSTOR PROCESSING AND MATERIAL PROPERTIES

\section{Material Processing}

The silicon nitride material used to manufacture the combustor was Kyocera SN251. The combustor was processed by the general flow diagram shown in Fig. 1. A mixture of silicon nitride $\left(\mathrm{Si}_{3} \mathrm{~N}_{4}\right)$ powder, sintering aids and a polymeric binder were milled. The resulting slurry was dried, granulated and cold isostatically pressed to form a cylindrical tube. The tube was green machined to near final shape, dewaxed, and sintered in a nitrogen atmosphere. Final machining produced the combustor shown in Fig. 2 .

\section{Mechanical Properties}

Mechanical properties necessary for the FEM and reliability analyses were experimentally determined. The parameters required for stress analysis included Young's modulus, Poisson's ratio, thermal conductivity, thermal expansion coefficient and specific heat. The CARES analysis requires strength data (from which the Weibull parameters are calculated) and Poisson's ratio. Fracture toughness was also measured. Although this parameter is not required 
for predictions made by CARES, it is used in life-time prediction and is related to the properties used in the reliability analysis. Strength measurements, which are the basis of reliability predictions, are controlled by both the flaws inherent in ceramic materials and the fracture toughness. Toughness represents the ability of a material to tolerate flaws and thus can be considered in long term applications.

Young's modulus and Poisson's ratio between room temperature (RT) and $1400{ }^{\circ} \mathrm{C}$ were determined by a resonance method in accordance with ASTM C848-78 (4). For comparison, room temperature Young's modulus was also determined by strain gaging a four-point bend specimen. Poisson's ratio was also determined with an ultrasonic pulse method at room temperature. Thermal expansion was measured as a function of temperature via a differential transformer. Thermal conductivity and specific heat were obtained as a function of temperature via the laser flash method (5).

Test specimens for strength and fracture toughness measurements were machined from the combustor liner and heat treated in air at $1150{ }^{\circ} \mathrm{C}$ for $1.5 \mathrm{hr}$ to eliminate machining damage. The flexure strength was determined in four-point bending in accordance with JIS (6) at temperatures of 25, 1000 and $1371^{\circ} \mathrm{C}$. The specimens measured $3 \times 4 \mathrm{~mm}$ in height and width and the inner and outer spans were 10 and $30 \mathrm{~mm}$, respectively. A minimum of $27 \mathrm{strength}$ tests were run at each temperature. Flaw type and location (connected to the surface or completely within the volume) were determined with optical microscopy or scanning electron microscopy as necessary.

Fracture toughness was determined with the single-edge-precracked-beam (SEPB) (7) and chevron-notch $(7,8)$ methods in three-point bending. Specimens were $3 \times 4 \times 30 \mathrm{~mm}$ in thickness, width and span. The SEPB specimens were tested at a stroke rate of $0.5 \mathrm{~mm} / \mathrm{min}$. Chevron-notch specimens were tested at 
$0.005 \mathrm{~mm} / \mathrm{min}$. The low stroke rate used for chevron-notch testing was required to insure stable crack extension.

$\underline{\text { Results and Discussion }}$

Young's modulus, Poisson's ratio, thermal expansion, thermal conductivity and specific heat are illustrated in Figs. 3 to 5 as functions of temperature. Young's modulus exhibited a continuous drop with temperature. The room temperature, mechanically and sonically determined values were within 3 percent. Poisson's ratio was almost constant. The thermal expansion increased linearly with temperature, resulting in a coefficient of $3.1 \times 10^{-6} /{ }^{\circ} \mathrm{C}$. The thermal conductivity exhibited a gradual drop with increasing temperature, while the specific heat increased gradually with temperature.

A summary of bend strength test results is given in Table I. Both the characteristic strength, $\sigma_{\theta}$, and Weibull modulus, m, decreased with temperature. The characteristic strength is the stress at which 63.2 percent of the specimens failed. This strength parameter is dependent on specimen volume and should not be confused with the scale parameter which is independent of volume.

Failure originated from either a large, 30 to $100 \mu \mathrm{m}$ grain with a hexagonal cross section, or a 15 to $70 \mu \mathrm{m}$ diameter pore. Examples of failure origins are shown in Figs. 6(a) and (b).

The population of volume type failures observed at 25 and $1000{ }^{\circ} \mathrm{C}$ was insufficient for statistical characterization. However, nearly 50 percent of the specimens failed from volume flaws at $1371{ }^{\circ} \mathrm{C}$. This change from surface to volume failure indicated healing of surface connected flaws. Six specimens out of 31 tested at $25^{\circ} \mathrm{C}$ and three specimens out of 27 tested at $1000^{\circ} \mathrm{C}$ failed from processing flaws connected to the beveled edges of the specimens. These failures were classified as surface failures. 
Fracture toughness results are summarized in Table II. The chevron-notch specimens exhibited nonlinear load-displacement diagrams, indicating stable crack extension. Fracture toughness, calculated from maximum load and minimum stress intensity coefficient, decreased with temperature up to $1200{ }^{\circ} \mathrm{C}$. However, at $1371^{\circ} \mathrm{C}$ the load-displacement diagrams became severely nonlinear and the toughness appeared to increase substantially. Evidently, the combination of slow stroke rate and high temperature resulted in creep deformation instead of stable fracture.

Room temperature fracture toughness measured with the SEPB was comparable to that of the chevron-notch. However, SEPB measurements at $1371{ }^{\circ} \mathrm{C}$ were much lower and comparable to the value measured with the chevron-notch at $1200{ }^{\circ} \mathrm{C}$. The SEPB produced fast fracture at $1371^{\circ} \mathrm{C}$, while the chevron-notch allowed creep deformation instead of stable fracture.

\section{COMBUSTOR ANALYSIS}

\section{FEM Stress Analysis}

Before performing the reliability evaluation with CARES, both the mechanical and thermal stresses in the CGT combustor were analyzed. The thermal stresses were especially significant for the combustor. Empirically, the critical stress of the combustor was expected to occur around the dilution port due to cooling. When an engine is shut-down, fuel is cut off and the combustor cools rapidly because of the injection of fresh air. The resulting thermal shock phenomenon produces high, transient tensile stresses on the surface. The FEM analysis was designed to simulate the worst transient thermal stress in an emergency stop.

Figure 7 shows the finite element model of the combustor. Exploiting symmetry, only $1 / 16$ of the combustor was discretized. Table III shows gas temperatures and heat transfer coefficients for both steady state and transient conditions. 
temperatures and heat transfer coefficients for both steady state and transient conditions.

Gas temperature during running was set at $1350{ }^{\circ} \mathrm{C}$ for the inside of the combustor and at $913{ }^{\circ} \mathrm{C}$ for the outside and the primary hole. The heat transfer coefficient was assumed to be the same for the steady state and transient conditions.

Figure 8 shows the steady state temperature distribution obtained by the FEM analysis. There was less than a $70{ }^{\circ} \mathrm{C}$ temperature difference in the combustor. Thus, the resulting stress level was relatively low, with a maximum of $60 \mathrm{MPa}$ located at the edge of the primary hole.

During the transient stage, however, the maximum principal stress of this part changed with time and reached a peak value of $163 \mathrm{MPa}$ after $30 \mathrm{sec}$, as shown in Fig. 9. Figures 10 and 11 show the temperature distribution and the maximum principal stress, respectively, at $30 \mathrm{sec}$. There was almost a $200{ }^{\circ} \mathrm{C}$ temperature difference between the primary hole and the bottom of the combustor. This large temperature difference resulted in the high tensile stress at the edge of the primary hole.

These results indicated relatively low stresses at steady state and higher stresses after combustor shut down. Thus, the reliability analysis in this study concentrated on the tensile stress state at $30 \mathrm{sec}$ after shut down. Description of the CARES Program

The CARES program is based on the theory proposed by Batdorf (9) in which linear elastic fracture mechanics (LEFM) is used to derive multiaxial effective stress equations. The critical stress of a crack is defined as a remote, uniform uniaxial stress which causes fracture when applied normal to the crack plane. With the assumption that the cracks are randomly oriented, the effective stress equations are used to calculate the probability that a crack 
with a given critical stress level is oriented with respect to the applied loads such that it would cause fracture. This orientation probability is multiplied by a crack existence probability, namely the probability that a crack with a given critical stress exists.

For structural applications, integration must be performed over the volume of the component to account for the variation in stress with location. In CARES, the results of finite element analysis are used for this purpose.

To apply the Batdorf theory to a practical problem, one must make simplifying assumptions about the type of flaws present in the material. In the CARES program, several different flaws types are available. It is usually recommended that penny-shaped and semicircular cracks be used in the volume and surface analyses, respectively, as they are more representative of small embedded flaws.

Further assumptions must be made about the condition that will lead to fracture. The LEFM criteria available in CARES include the normal stress criterion, the total strain energy release rate criterion, the maximum principal stress criterion, the principle of independent action (PIA) criterion, and a mixed-mode interaction equation called Shetty's criterion (10). Shetty's criterion can be used with a constant, C, defined as the ratio of fracture toughness in pure mode II loading and the mode I fracture toughness. The constant can be selected to fit data from mixed-mode fracture toughness testing, or selected so that this criterion simulates out-of-plane crack extension theories, including the maximum strain energy release rate $\left(G_{\max }\right)$ criterion.

The material parameters which describe the variability in strength must be obtained from fracture strength measurements. The measurements usually have a mixture of volume and surface failure origins. The locations of these 
origins may be distinguished (censored data) or ignored (uncensored data). The distribution of strength is of ten described with Weibull modulus, m, and characteristic strength, $\sigma_{\theta}$. CARES can estimate these parameters by either maximum likelihood (ML) or a least squares fitting (LS) technique.

For the reliability analysis, the characteristic strength is not directly used, as it depends on the effective volume or surface area of the test specimen. Instead, the value corresponding for a uniformly stressed specimen of unit volume or area, the scale parameter, is used. The scale parameter is theoretically independent of the material volume tested, however, it must be calculated from the characteristic strength and Weibull modulus and depends upon the assumption that the Weibull weakest link theory is valid.

For the Batdorf theory, the probability of a crack existing is assumed to be proportional to a crack density function coefficient, $k_{B}$. This coefficient is determined from the characteristic strength by equating the Batdorf and the Weibull failure probabilities for the given test conditions. It should be noted that the value of $\mathrm{k}_{\mathrm{B}}$ depends on the fracture criterion that is used in this calculation. There are two methods available in CARES for calculating $\mathrm{k}_{\mathrm{B}}$. The first one assumes that in uniaxial loading only mode I fracture can occur. This restriction is due to the assumption that a sufficient number of large cracks are oriented perpendicular to the loading direction, and that these will preferentially fail. This method results in a shear-insensitive crack density coefficient. The second technique assumes that the selected mixed-mode fracture criterion is equally applicable for uniaxial and multiaxial loading. This shear sensitive method will always lead to a lower crack density coefficient and a lower resultant multiaxial failure probability. Failure Probabilities

Statistical parameters. The rationale to be used in the selection of material parameters for reliability calculations is not straight forward. 
Goodness-of-fit tests provide some indication of whether the ML or LS parameters are better suited for the data at hand.

Our rationale used in choosing material parameters for the reliability calculations was to provide conservative values of failure probabilities of the component. In the low failure probability regime, a lower value of the Weibull modulus results in higher failure probabilities. Failure probabilities are not strongly dependent on the characteristic strength, whereas the Weibull modulus has a much more significant effect. In accordance with the aforementioned arguments, LS parameters were chosen for the analyses.

In this case, the lack of volume flaw data at RT and $1000{ }^{\circ} \mathrm{C}$ caused both ML and LS parameters to be questionable, resulting in undependable goodness-of-fit tests. Thus, the volume flaw characteristic strength and Weibull modulus at $1000{ }^{\circ} \mathrm{C}$ were obtained by graphical interpolations of the corresponding values at RT and $1371^{\circ} \mathrm{C}$, as shown in Fig. 12 and listed in Table I.

For comparison, the data was also analyzed without censoring, i.e., fracture origins were not considered. Obtained parameters are listed in Table IV.

$\underline{\text { Results and discussion. The failure probabilities resulting for several }}$ fracture criteria are listed in Table V. Very small failure probabilities were obtained for all criteria. Failure probabilities were larger for the surface analysis than the volume analysis in all cases. The maximum total failure probability was $2.463 \times 10^{-9}$ for Shetty's semi-empirical case with $\mathrm{C}=0.80$, and the minimum failure probability was $6.962 \times 10^{-10}$ for the PIA model.

Parameters obtained from the uncensored data were also used to calculate the reliability of the component. For uncensored data, the estimated failure probabilities for Shetty's semi-empirical case were $1.106 \times 10^{-13}$ and $2.315 \times 10^{-12}$ 
for volume and surface analyses, respectively (see Table VI), using LS parameters. Comparing these values with the corresponding ones in Table V, it is evident that there are large differences in the failure probabilities for censored and uncensored data. Although parameters determined from uncensored data may have reasonable statistical characteristics because of the larger sample size, differences can arise with such simplifying assumptions.

Additional calculations of the worst case situation were made by selecting the 90 percent lower confidence limits of the Weibull moduli and characteristic strengths obtained by ML. The 90 percent limits are not available from the CARES program for sample sizes smaller than five. For these cases the 90 percent lower bound was estimated using the same factors that would have been used for a sample size of five. The failure probability increased to $5.302 \times 10^{-6}$ for this extreme condition, as shown in Table VI. The calculated stresses may depend on the FEM mesh used. In this case, the calculated stresses are concentrated on the edge of the hole. The differences in stress states may be enhanced by raising them to the power of the Weibull modulus. Failure probabilities for a Standard (coarse) and a fine mesh are listed in Tables V and VI for Shetty's failure criterion. The failure probabilities obtained with the fine mesh were smaller than those of the standard mesh.

All of the above calculations resulted in very small failure probabilities of the combustor, even for the worst case calculation. Thus, it is concluded that this combustor can safely operate under the assumed loading conditions. CONCLUSIONS

Calculations of statistical parameters and failure probabilities for a SN251 combustor were performed with the CARES computer code. The failure probabilities under extreme operating conditions were presented assuming a 
worst case scenario. From these calculations it was concluded that this combustor can be safely operated for the short-term under the assumed conditions. It should be emphasized that a quantitative estimate of the failure probability gives good guidance for designing ceramic components. The importance of statistical analysis, and censoring of volume and surface flaws were demonstrated. Simple bend tests did not provide sufficient volume fracture data for this analysis. To obtain more volume fracture data, tensile testing may be required.

In this paper, only the fast fracture failure mode was considered. For the lifetime evaluation of such components, additional fatigue testing as well as further theoretical work are required.

\section{REFERENCES}

1. Weibull, W., 1939, "A Statistical Theory of the Strength of Materials," Ingeniors Vetenskaps Akademien Handlinger, No. 151.

2. Gyekenyesi, J.P., 1986, "SCARE: A Postprocessor Program to MSC/NASTRAN for Reliability Analysis of Structural Ceramic Components," Lournal of Engineering for Gas Turbines and Power, Vol. 108, No. 3, 1986, pp. 540-546.

3. Nemeth, N., Manderscheid, J., Gyekenyesi, J., 1989, "Ceramics Analysis and Reliability Evaluation of Structures (CARES) User's and Programmers Manual," NASA TP-2916.

4. "Young's Modulus, Shear Modulus, and Poisson's Ratio for Ceramic Whitewares by Resonance," ASTM Standard Test Method C848-78. 1984 Annual Book of ASTM Standards, Section 15.02. American Society for Testing and Materials, Philadelphia, PA.

5. Hirai, T., Hayashi, S., and Ni ihara, K., 1978, "Thermal-Diffusivity, Specific-Heat and Thermal-Conductivity of Chemical Vapor-Deposited $\mathrm{Si}_{3} \mathrm{~N}_{4}$," American Ceramic Society Bulletin, Vol. 57, No. 12, pp. 1126-30. 
6. Japanese Industrial Standard JIS R 1601-1981, Japanese Standards As sociation, 1981 .

7. Nose, T., and Fujii, T., 1988, "Evaluation of Fracture Toughness for Ceramic Materials by a Single-Edge-Precracked-Beam Method," Lournal of the American Ceramic Society, Vol. 71, No. 5, pp. 328-33.

8. Munz, D., Bubsey, T., and Shannon, Jr., J.L., 1980, "Fracture-Toughness Determination of $\mathrm{Al}_{2} \mathrm{O}_{3}$ Using Four-Point-Bend Specimens with Straight Through and Chevron-Notches," Lournal of the American Ceramic Society Vol. 63, No. 5 and 6, pp. 300-305.

9. Batdorf, S.B., and Heinsch. H.L., 1978, "Weakest Link Theory Reformulated for Arbitrary Fracture," Journal of the American Ceramic Society, Vol. 61, No. 7 and 8 , pp. 355-358.

10. Shetty, D.K., 1987, "Mixed Mode Fracture Criteria for Reliability Analysis and Design with Structural Ceramics," Journal of Engineering for Gas Turbines and Power, Vol. 109, No. 3, pp 282-289. 
TABLE I. - BEND STRENGTH TEST RESULTS

\begin{tabular}{|c|c|c|c|c|c|c|}
\hline & & & Least & uares fit & Maximu & i kel i hood \\
\hline $\begin{array}{l}\text { Temper- } \\
\text { ature, } \\
{ }^{\circ} \mathrm{C}\end{array}$ & $\begin{array}{l}\text { Flawa } \\
\text { location }\end{array}$ & $\begin{array}{l}\text { Number of } \\
\text { specimens }\end{array}$ & $\begin{array}{l}\sigma_{\Theta} \\
\mathrm{MPa}\end{array}$ & $\begin{array}{l}\text { Weibull } \\
\text { modulus }\end{array}$ & $\begin{array}{l}\sigma_{\theta} \\
\mathrm{MPa}\end{array}$ & $\begin{array}{l}\text { Weibull } \\
\text { modulus }\end{array}$ \\
\hline 25 & $\begin{array}{l}\text { S } \\
\text { V } \\
\text { U }\end{array}$ & $\begin{array}{r}26 \\
3 \\
2\end{array}$ & $\begin{array}{l}694 \\
752\end{array}$ & $\begin{array}{l}18.36 \\
21.44\end{array}$ & $\begin{array}{l}694 \\
749\end{array}$ & $\begin{array}{l}18.65 \\
32.44\end{array}$ \\
\hline 1000 & $\begin{array}{l}\text { S } \\
\text { V } \\
\text { U }\end{array}$ & $\begin{array}{r}26 \\
1 \\
0\end{array}$ & $\begin{array}{r}591 \\
b_{623}\end{array}$ & $\begin{array}{r}13.78 \\
b_{17} .00\end{array}$ & $\begin{array}{r}592 \\
b_{623}\end{array}$ & $\begin{array}{r}13.33 \\
\mathrm{~b}_{23.80}\end{array}$ \\
\hline 1371 & $\begin{array}{l}\text { S } \\
\text { V } \\
\text { U }\end{array}$ & $\begin{array}{r}29 \\
21 \\
0\end{array}$ & $\begin{array}{l}565 \\
585\end{array}$ & $\begin{array}{l}10.12 \\
13.95\end{array}$ & $\begin{array}{l}574 \\
585\end{array}$ & $\begin{array}{r}8.86 \\
15.31\end{array}$ \\
\hline
\end{tabular}

as = surface flaw; $V=$ volume flaw; $U=$ unknown origin.

bInterpolated values (see section 3 and $3(a)$ ).

TABLE I I . - FRACTURE TOUGHNESS DATA

\begin{tabular}{|l|c|c|c|}
\hline \multicolumn{1}{|c|}{$\begin{array}{c}\text { Test } \\
\text { method }\end{array}$} & $\begin{array}{c}\text { Temperature, } \\
{ }^{\circ} \mathrm{C}\end{array}$ & $\begin{array}{c}\text { Number } \\
\text { of tests }\end{array}$ & $\begin{array}{c}\text { KIc, } \\
\mathrm{MPa}^{*} \mathrm{~m} \cdot 5\end{array}$ \\
\hline Chevron & 25 & 5 & 7.9 \\
notch & 800 & 5 & 7.1 \\
& 1000 & 3 & 6.9 \\
& 1200 & 4 & 6.0 \\
& 1371 & 2 & 10.4 \\
\hline SEPB & 25 & 7 & 7.4 \\
& 1371 & 4 & 6.1 \\
\hline
\end{tabular}

TABLE I I . - GAS TEMPERATURE AND HEAT TRANSFER COEFFICIENTS

\begin{tabular}{|c|c|c|c|}
\hline & Inside & Outside & Primary hole \\
\hline $\begin{array}{c}\text { Heat transfer } \\
\text { coefficient } \\
\left(\mathrm{W} / \mathrm{m}^{2} \mathrm{~K}\right)\end{array}$ & 85.5 & 113.3 & 1032 \\
\hline \multicolumn{3}{|c|}{ Gas temperature, ${ }^{\circ} \mathrm{C}$} \\
\hline $\begin{array}{c}\text { Steady } \\
\text { state } \\
\begin{array}{c}\text { Transient } \\
\text { state }\end{array}\end{array}$ & 1350 & 913 & 913 \\
\hline
\end{tabular}


TABLE IV. - UNCENSORED WEIBULL PARAMETERS BY THE LEAST SQUARES METHOD

\begin{tabular}{|c|c|c|c|}
\hline $\begin{array}{c}\text { Temperature, } \\
{ }^{\circ} \mathrm{C}\end{array}$ & $\begin{array}{c}\text { Scale parameter, } \\
\operatorname{MPa}\left(\mathrm{mm}^{2}\right)^{1 / \mathrm{m}}\end{array}$ & $\begin{array}{c}\sigma_{\theta}, \\
\mathrm{MPa}\end{array}$ & $\begin{array}{c}\text { Weibull modulus, } \\
\mathrm{m}\end{array}$ \\
\hline 25 & 844 & 690 & 18.90 \\
1000 & 776 & 590 & 14.05 \\
1371 & 770 & 544 & 11.25 \\
\hline
\end{tabular}

TABLE V. - FAILURE PROBABILITY OF THE COMBUSTOR PREDICTED USING THE CARES CODE

\begin{tabular}{|l|c|c|c|}
\hline \multicolumn{1}{|c|}{ Criteria } & Volume & Surface & Total \\
\hline $\begin{array}{l}\text { Shetty's semi-empirical } \\
\text { Penny shape (semi-circular) } \\
\text { Mode I fracture }\end{array}$ & $1.823 \times 10^{-11}$ & $2.445 \times 10^{-9}$ & $2.463 \times 10^{-9}$ \\
\hline $\begin{array}{l}\text { Shetty's semi-empirical } \\
\text { Penny shape (semi-circular) } \\
\text { Shear sensitive }\end{array}$ & $3.874 \times 10^{-13}$ & $7.719 \times 10^{-10}$ & $7.723 \times 10^{-10}$ \\
\hline $\begin{array}{l}\text { Strain energy release rate } \\
\text { Penny shape (semi-circular) } \\
\text { Mode I fracture }\end{array}$ & $1.146 \times 10^{-12}$ & $9.929 \times 10^{-12}$ & $9.940 \times 10^{-10}$ \\
\hline $\begin{array}{l}\text { Strain energy release rate } \\
\text { Penny shape (semi-circular) } \\
\text { Shear sensitive }\end{array}$ & $4.217 \times 10^{-13}$ & $7.050 \times 10^{-10}$ & $7.055 \times 10^{-10}$ \\
\hline Normal stress fracture & $5.223 \times 10^{-13}$ & $7.001 \times 10^{-10}$ & $7.006 \times 10^{-10}$ \\
\hline $\begin{array}{l}\text { Maximum tensile } \\
\text { Penny shape (semi-ciruclar) }\end{array}$ & $9.954 \times 10^{-13}$ & $7.001 \times 10^{-10}$ & $7.011 \times 10^{-10}$ \\
\hline PIA model & $5.246 \times 10^{-13}$ & $6.957 \times 10^{-10}$ & $6.962 \times 10^{-10}$ \\
\hline
\end{tabular}


TABLE VI. - FAILURE PROBABILITIES PREDICTED USING THE CARES CODE

[Criteria: Shetty's semi-empirical mode I fracture criterion penny shape (semi-circular).]

\begin{tabular}{|l|c|c|c|}
\hline & Volume & Surface & Total \\
\hline Uncensored & $1.106 \times 10^{-13}$ & $2.315 \times 10^{-12}$ & $2.426 \times 10^{-12}$ \\
\hline $\begin{array}{l}\text { Extreme Weibull } \\
\text { modulus }\end{array}$ & $2.888 \times 10^{-12}$ & $5.302 \times 10^{-6}$ & $5.302 \times 10^{16}$ \\
\hline Refined mesh & $1.249 \times 10^{-16}$ & $4.976 \times 10^{-12}$ & $4.976 \times 10^{-12}$ \\
\hline $\begin{array}{l}\text { Refined mesh } \\
\text { wi th extreme } \\
\text { Weibull modulus }\end{array}$ & $1.665 \times 10^{-16}$ & $2.482 \times 10^{-8}$ & $2.482 \times 10^{-8}$ \\
\hline
\end{tabular}




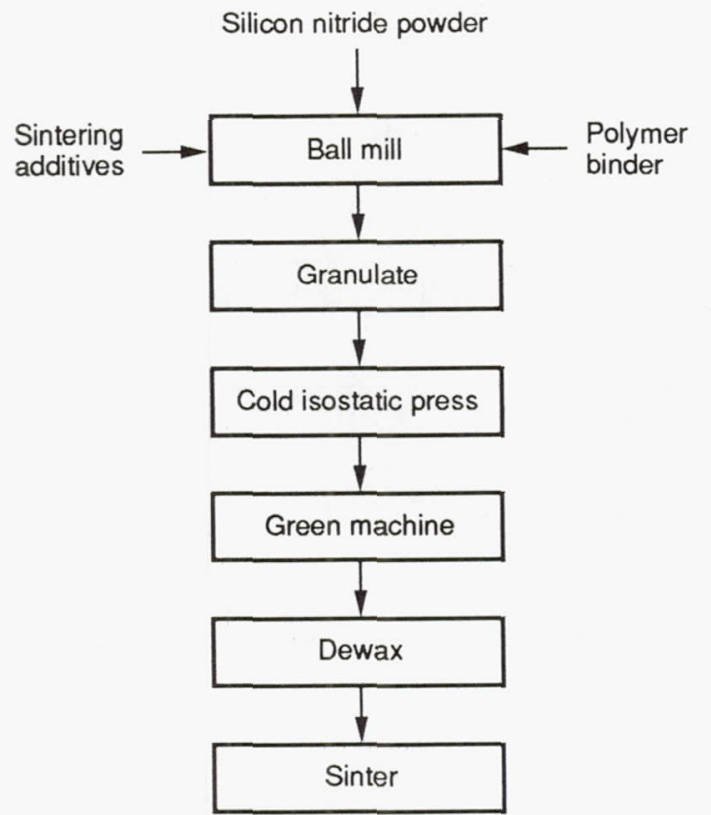

Figure 1.-Flow diagram for processing the SN251 silicon nitride combustor.

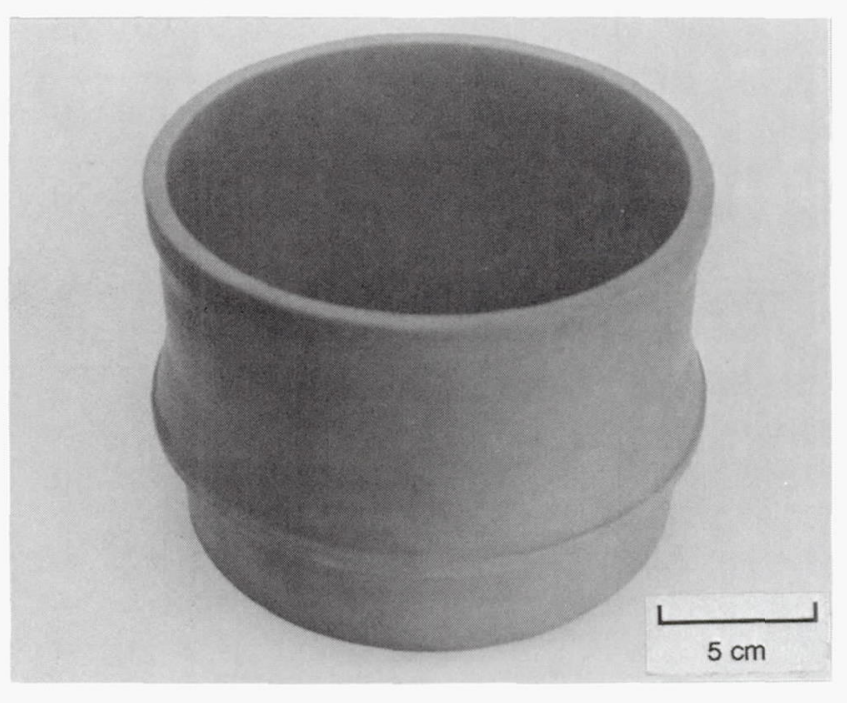

Figure 2.-View of the SN251 silicon nitride combustor.

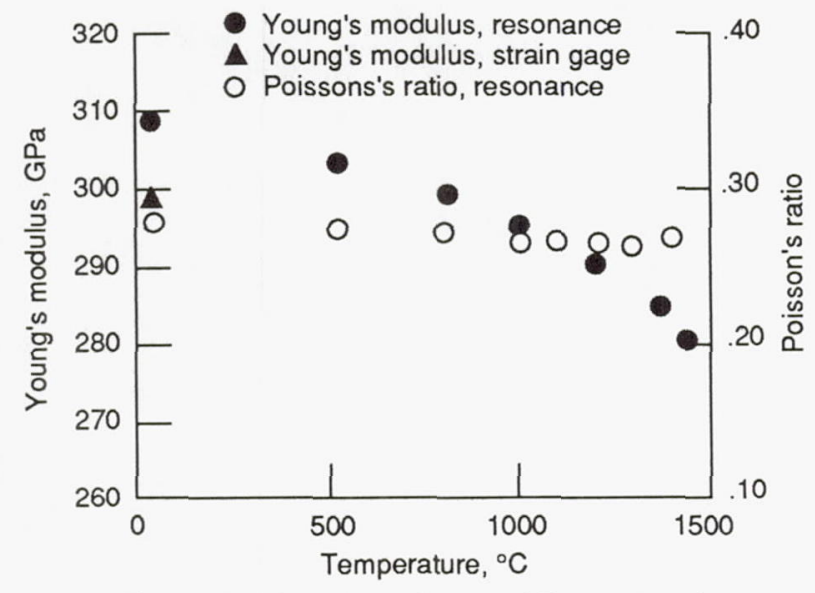

Figure 3.-Young's modulus and Poisson's ratio of SN251 as a function of temperature.

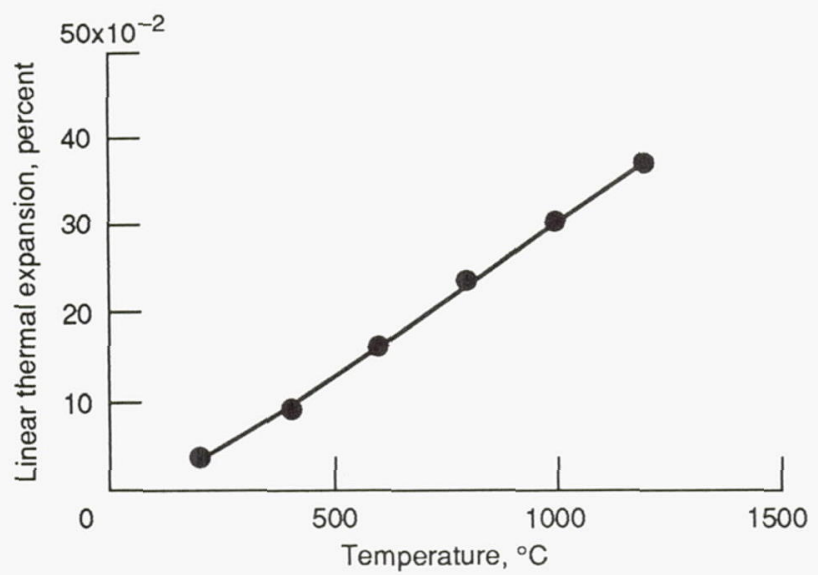

Figure 4.-Thermal expansion of SN251 as a function of temperature. 


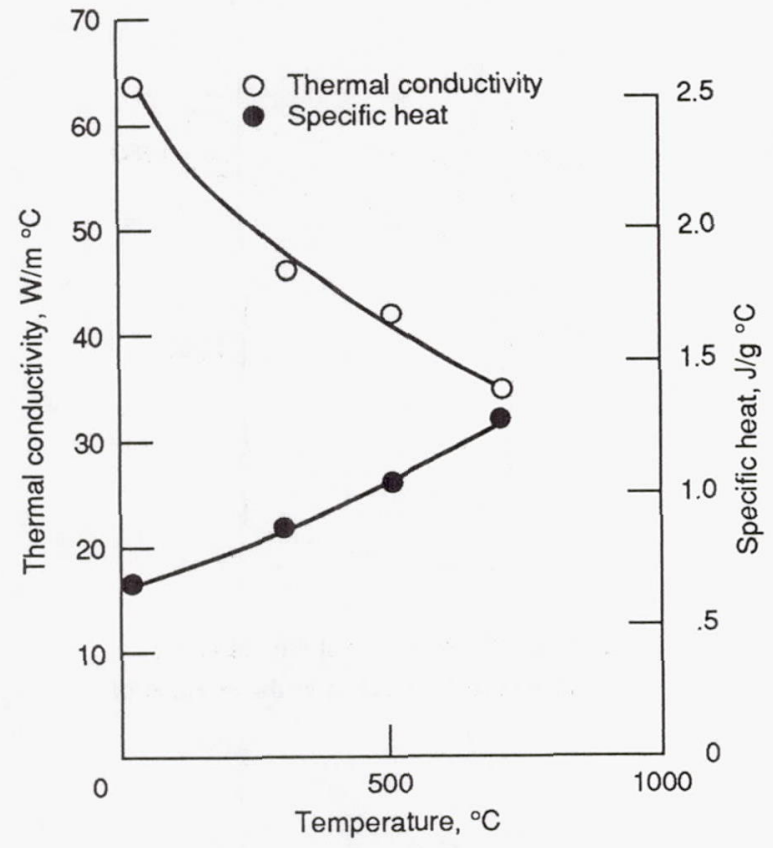

Figure 5.-Thermal conductivity and specific heat of SN251 as a function of temperature.

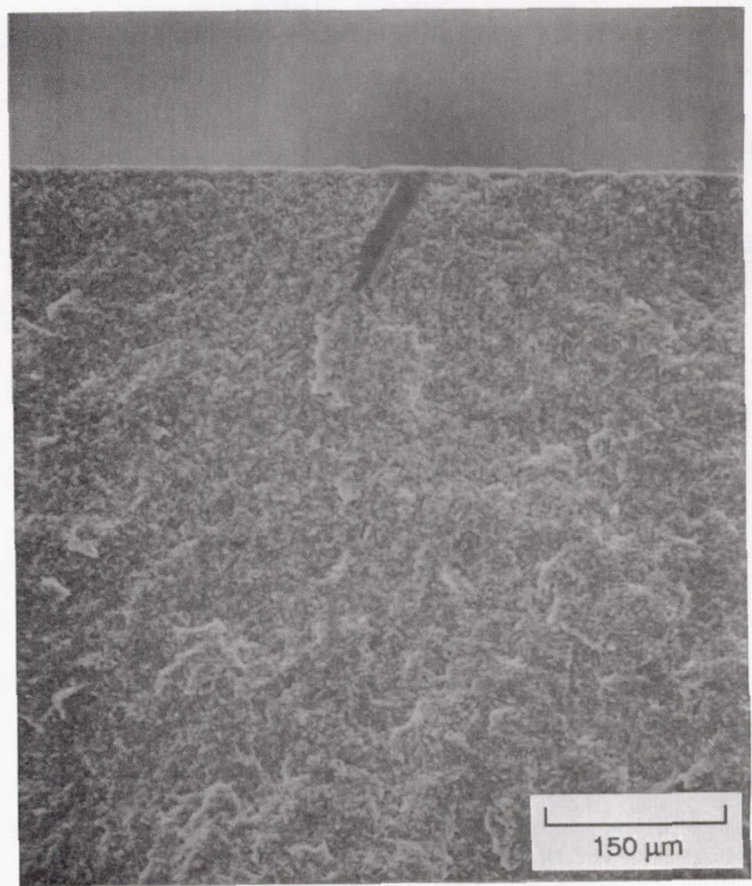

(a) Large, surface connected grain.

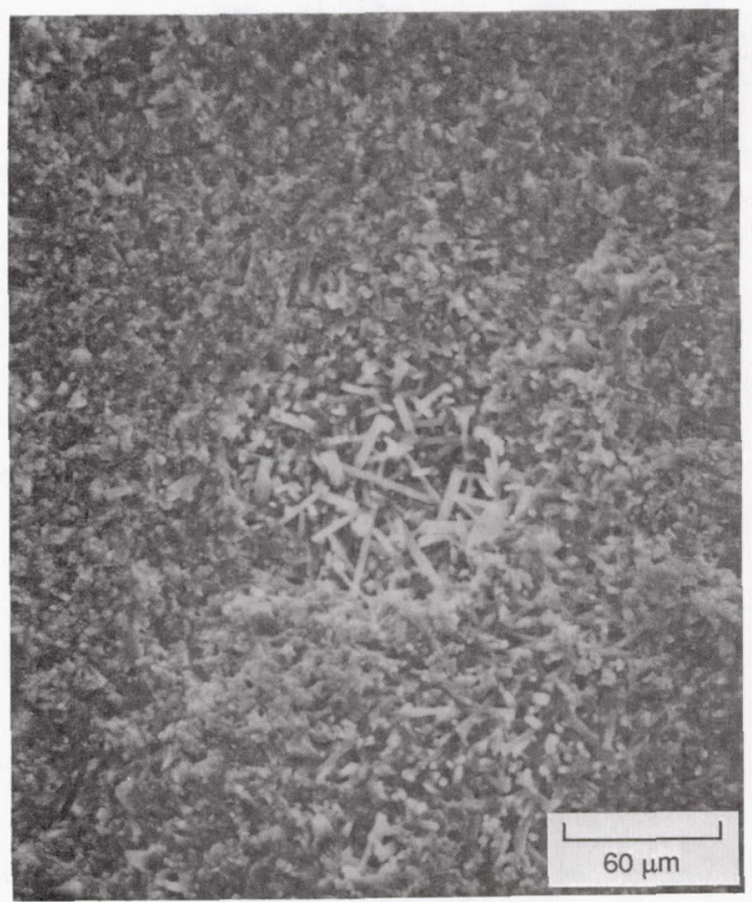

(b) Volume pore

Figure 6.-Failure origins. 


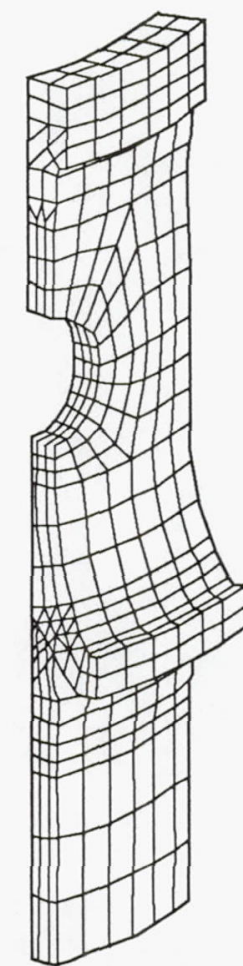

Figure 7.-Finite element mesh of a $1 / 16$ section of the combustor.

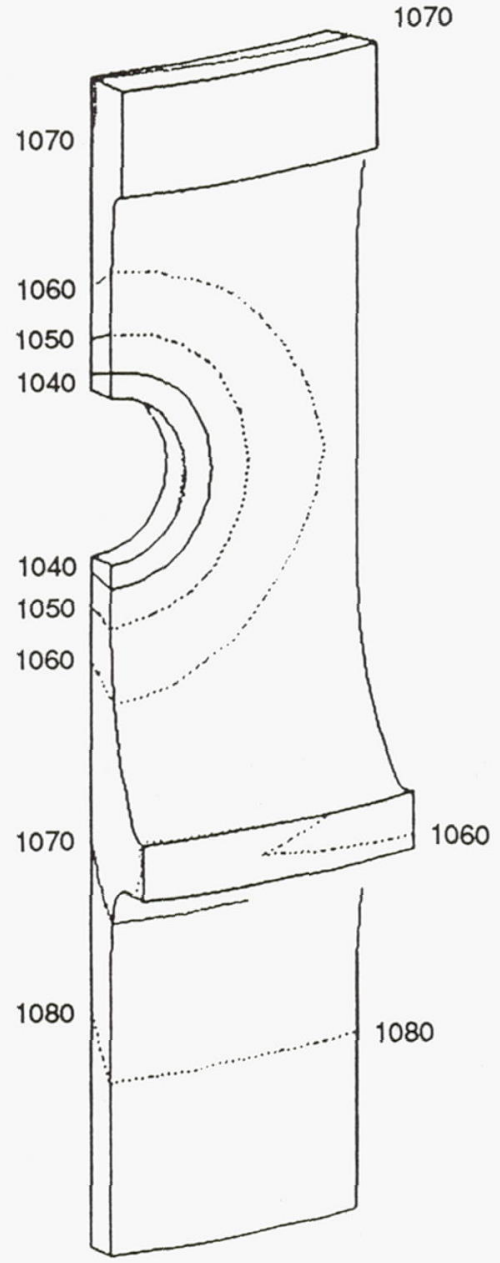

Figure 8.-Contour plot of the steady state temperature distribution in the combustor.

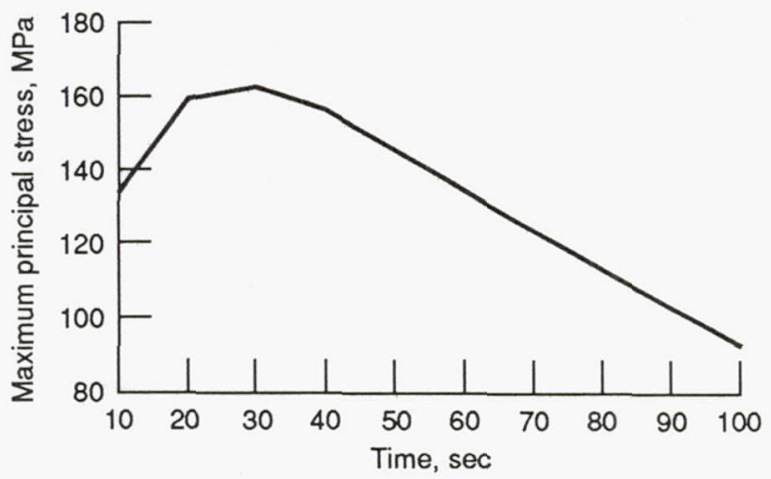

Figure 9.-Maximum principal stress in the combustor as a function of time. 


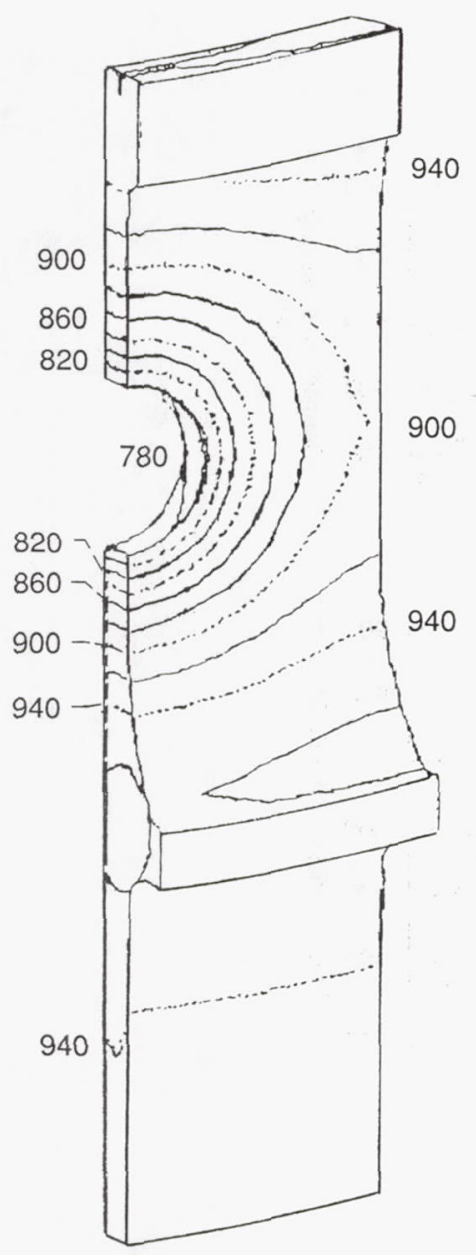

Figure 10.-Temperature distribution $\left({ }^{\circ} \mathrm{C}\right)$ at the peak value of the maximum principal stress.

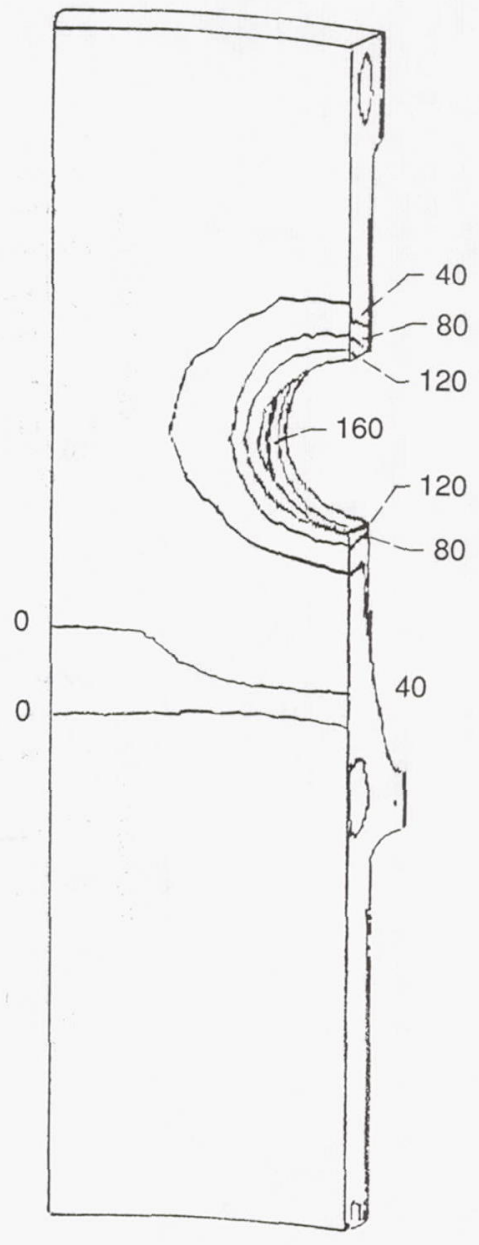

Figure 11.-Maximum principal stress distribution (MPa) occurring $30 \mathrm{sec}$ after engine shut-down. 

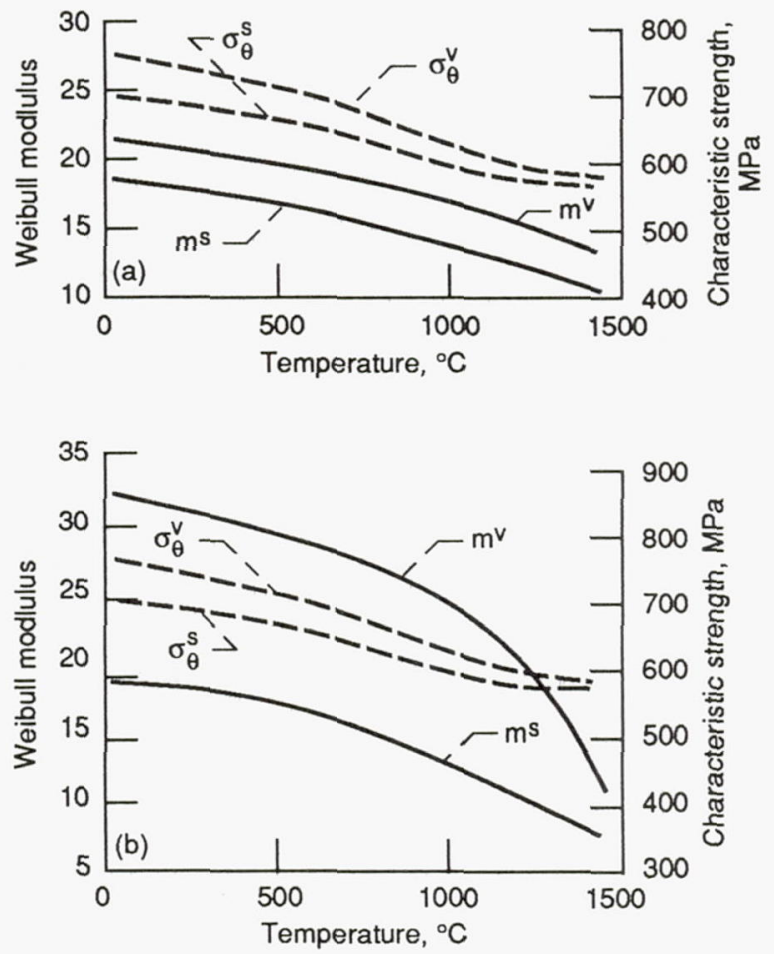

Figure 12. 


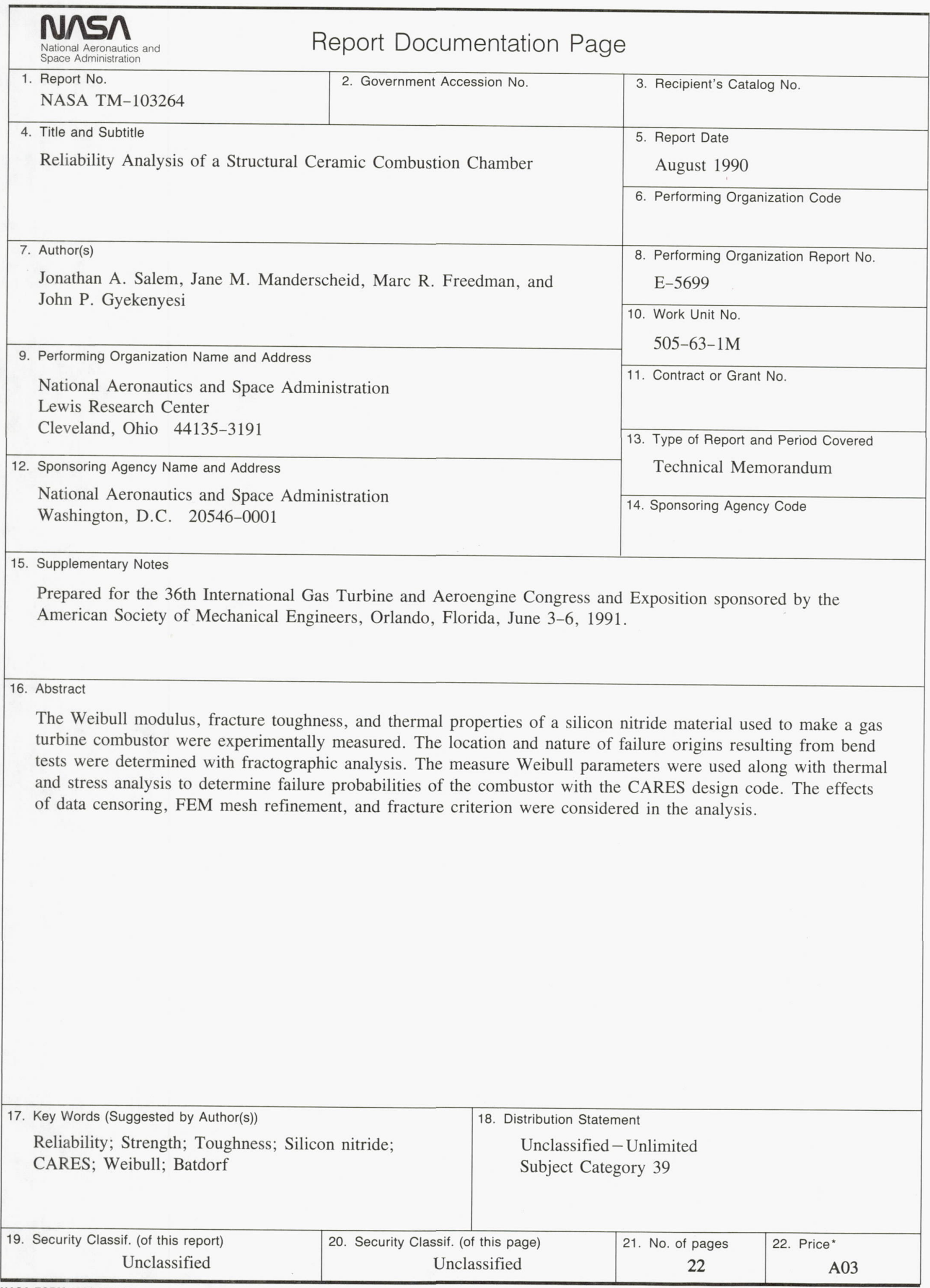

